PRPAT

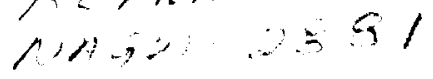
$\therefore N-\because \cdots$ E. 2, : $\cdots, \cdots \cdots$

\title{
Extraterrestrial Helium Trapped in Fullerenes in the Sudbury Impact Structure
}

\author{
Luann Becker," Robert J. Poreda, and Jeffrey L. Bada
}




\title{
Extraterrestrial Helium Trapped in Fullerenes in the Sudbury Impact Structure
}

\author{
Luann Becker, ${ }^{\star}$ Robert J. Poreda, Jeffrey L. Bada
}

Fullerenes $\left(\mathrm{C}_{60}\right.$ and $\left.\mathrm{C}_{70}\right)$ in the Sudbury impact structure contain trapped helium with a ${ }^{3} \mathrm{He} /{ }^{4} \mathrm{He}$ ratio of $5.5 \times 10^{-4}$ to $5.9 \times 10^{-4}$. The ${ }^{3} \mathrm{He} /{ }^{4} \mathrm{He}$ ratio exceeds the accepted solar wind value by 20 to 30 percent and is higher by an order of magnitude than the maximum reported mantle value. Terrestrial nuclear reactions or cosmic-ray bombardment are not sufficient to generate such a high ratio. The ${ }^{3} \mathrm{He} /{ }^{4} \mathrm{He}$ ratios in the Sudbury fullerenes are similar to those found in meteorites and in some interplanetary dust particles. The implication is that the helium within the $\mathrm{C}_{60}$ molecules at Sudbury is of extraterrestrial origin.

Fullerenes $\left(C_{00}\right.$ and $\left.C_{70}\right)$ have recently been identified in a shock-produced breccia (Onaping Formation) associated with the 1.85-billion-year-old Sudbury impact structure (1). The presence of 1 to 10 parts per million (ppm) (1) of fullerenes in these samples from the Onaping Formation raises questions about the origin of fullerenes and about the potential for delivery of intact organic material to Earth by a large bolide (for example, an asteroid or comet). Because the Sudbury target rocks are poor in carhon $(\mathrm{C})$, we have suggested that the fullerene $C$ was extraterrestrial in origin (1). There are two possible scenarios for the presence of fullerenes in the Sudbury impact deposits: (i) that fullerenes are synthesized within the impact plume from the C contained in the bolide (I), or (ii) that fullerenes were already present in the bolide and survived the impact event. We examine here these possible sources of the Sudbury fullerenes by searching for noble gases trapped inside the fullerene molecule.

The correlation of $C$ and trapped noble gas atoms in meteorites is well established (2). Primitive meteorites contain several trapped noble gas components that have anomalous isotopic compositions. For example, Black and Pepin (3) found anomalous $\mathrm{Ne}$ values in several primitive unmetamorphosed meteorites, and Anders and co-work-

L. Becker, Space Science Division. National Aeronautics and Space Administration Ames Research Center, Mollett Field, CA 94035. USA, and Scripps institution of Oceanography, University of California at San Diego. La Jolla, CA 92093-0212, USA.

R. J. Poreda. Department of Earth and Environmental Sciences, University of Rochester, Rochester, NY 14627. USA.

J. L. Bada, Scripps Institution of Oceanography, University of California at San Diego. La Jolla, CA 92093-0212. USA.

- To whorn correspondence should be addressed at Scripps. E-mail: lbecker@ucsd.edu ers (4) reported $\mathrm{Kr}$ and $\mathrm{Xe}$ values in the Murchison and Allende meteorites that are indicative of a presolar origin. Several Cbearing phases have been recognized as carriers of trapped noble gases, including $\mathrm{SiC}$, graphite, and diamond (5). Fullerenes have heen suggested as a carrier of noble gas components in carbonaceous chondrites (6); however, so far, the identification of fullerenes $\left(\mathrm{C}_{60}\right.$ and $\left.\mathrm{C}_{70}\right)$ is limited to a single occurrence in the Allende meteorite (7).

The $\mathrm{C}_{60}$ molecule is large enough to enclose the noble gases $\mathrm{He}, \mathrm{Ne}, \mathrm{Ar}, \mathrm{Kr}$, and $\mathrm{Xe}$ hut is too small to contain diatomic gases such as $\mathrm{N}_{2}$ or triatomic gases such as $\mathrm{CO}_{2}$. Recent experimental work has demonstrated that (i) $\mathrm{He}$ is incorporated into $\mathrm{C}_{60}$ during fullerene formation in a He atmosphere and (ii) noble gases of a specific isotopic composition can be introduced into synthetic fullerenes at high remperatures and pressures; these gases can then be released by the breaking of one or more $\mathrm{C}-\mathrm{C}$ bonds during step-heating under vacuum (8). The unique thermal release patterns for $\mathrm{He}$ encapsulated within the $\mathrm{C}_{(x)}$ molecule $\left(\mathrm{He} @ \mathrm{C}_{60}\right)$ are similar to the patterns for acid-resistant residues of carbonaceous chondrites (9), suggesting that fullerenes could he a carrier of trapped noble gases in metecrites.

To determine the noble gas abundances and isotopic ratios for the fullerenes, we undertook a systematic study of acid-resistant residues generated from samples collected at the Dowling and Capreol townships within the C-rich layer (Black Member) of the Onaping Formation (10). If the fullerenes were formed in the impact plume. then the isotopic ratios of the trapped gases would reflect the composition of Earth's atmosphere (that is, terrestrial) at the time of the impact. If, on the other hand, the fullerenes were present in the bolide before 
$\mathrm{C}_{\text {(o) }}$ molecule is also of extraterrestrial origin. In order to retain extraterrestrial $\mathrm{He}$, fullerenes must have survived the impact that produced the Sudbury crater (23).

If the fullerenes had formed as a result of the impact event, it seems likely that the ${ }^{3} \mathrm{He} /{ }^{4} \mathrm{He}$ ratio would reflect some contrihution from Earth's atmosphere, resulting in a ${ }^{3} \mathrm{He} /{ }^{4} \mathrm{He}$ ratio lower than solar wind vilues. The rigid-sphere incorporation model developed for the syntheric fullerenes (8) suggests that the probalility that a noble gas atom will be trapped within a fullerene molecule during formation is a funcrion of the size of the fullerene carity and the density of the gas. According to this model (8), the ${ }^{3} \mathrm{He}$ partial pressure for the Sudhury fullerenes at the time of formation is estimated to have been 0.5 torr (versus $10^{-10}$ torr in the present-day atmosphere), suggesting that a mechanism other than a terrestrial synthesis is needed. The ratios of the $C_{(x)}$ isotopic mass peaks for the fullerenes (1) show a possible enrichment in ${ }^{13} \mathrm{C}$, which would also indicate an extraterrestrial source of $C$.

Other possible terrestrial production mechanisms for the ${ }^{3} \mathrm{He}$, such as cosmic-ray bumbardment on Earth, may account for only a tiny fraction of the total ${ }^{3} \mathrm{He}$ in the $\mathrm{C}_{60}$ because surface exposure of the Sudhury rocks for more than $5 \times 10^{9}$ years would be necessary to generate the measured amount (24). Nuclear reactions in the terrestrial environment over geologic time are also capable of generating high ${ }^{3} \mathrm{He} /{ }^{4} \mathrm{He}$ ratios, and this process has been invoked to explain the high ${ }^{3} \mathrm{He} /{ }^{4} \mathrm{He}$ ratios determined in some diamonds (25). The dominant pro-

Table 1. Concentration of the He released during step-heating (17). The ${ }^{3} \mathrm{He} /{ }^{A} \mathrm{He}$ ratio $(R)$ is compared to the average value for terrestrial air $\left(R_{\text {arr }}\right)$.

\begin{tabular}{|c|c|c|c|c|}
\hline $\begin{array}{c}\text { Tem- } \\
\text { perature } \\
\left({ }^{\circ} \mathrm{C}\right)\end{array}$ & $\begin{array}{c}{ }^{3} \mathrm{He} \\
\left(10^{-9}\right. \\
\left.\mathrm{cm}^{3} / \mathrm{g}\right)\end{array}$ & $\begin{array}{c}{ }^{t} \mathrm{He} \\
\left(10^{-6}\right. \\
\left.\mathrm{cm}^{3} / \mathrm{g}\right)\end{array}$ & $\begin{array}{l}{ }^{3} \mathrm{He} /{ }^{\prime} \mathrm{He} \\
\left(R / R_{\text {air }}\right)\end{array}$ & $\begin{array}{l}\text { Fraction of } \\
{ }^{3} \mathrm{He} \text { released } \\
\text { per minute }\end{array}$ \\
\hline \multicolumn{5}{|c|}{ Dowling 1} \\
\hline 400 & 7.51 & 22.06 & 245 & 0.0018 \\
\hline 500 & 31.17 & 51.93 & 432 & 0.0046 \\
\hline 600 & 22.43 & 34.79 & 464 & 0.0043 \\
\hline 700 & 27.59 & 41.36 & 480 & 0.0069 \\
\hline 800 & 22.77 & 48.86 & 335 & 0.0138 \\
\hline 850 & 3.56 & 10.25 & 250 & 0.0167 \\
\hline Total & 115 & 209 & 393 & \\
\hline \multicolumn{5}{|c|}{ Capreol 2} \\
\hline 350 & 0.51 & 0.61 & 601 & 0.00012 \\
\hline 450 & 3.32 & 7.66 & 312 & 0.00082 \\
\hline 550 & 9.20 & 15.98 & 414 & 0.00239 \\
\hline 650 & 9.11 & 15.75 & 416 & 0.00276 \\
\hline 750 & 25.62 & 40.88 & 450 & 0.00932 \\
\hline 800 & 18.88 & 32.10 & 423 & 0.01557 \\
\hline 850 & 1.33 & 2.67 & 358 & \\
\hline Total & 68.0 & 115.6 & 423 & \\
\hline
\end{tabular}

duction mechanism is ${ }^{6} \mathrm{Li}+\mathrm{n} \rightarrow{ }^{3} \mathrm{He}+$ ${ }^{4} \mathrm{He}\left({ }^{3} \mathrm{H}\right.$ decays to ${ }^{3} \mathrm{He}$ ). However, in typical crustal rocks, the ${ }^{3} \mathrm{He} /{ }^{4} \mathrm{He}$ ratio of this nucleogenic component is $10^{-8}$, or $10^{-4}$ times that observed for Sudbury fullerenes. Experimental results (26) indicate that, even under ideal conditions in which the $\mathrm{Li}$ atom is attached to the $\mathrm{C}_{(x)}$ molecule and then irradiated with a low thermal neutron flux ( $10^{14}$ neutrons per square centimeter), only four ${ }^{3} \mathrm{H}$ atoms were incorporated per $10^{10} \mathrm{C}_{60}$ molecules. The irradiation also destroyed a large portion of the fullerenes. The experimental yield is only $11 \%$ of the
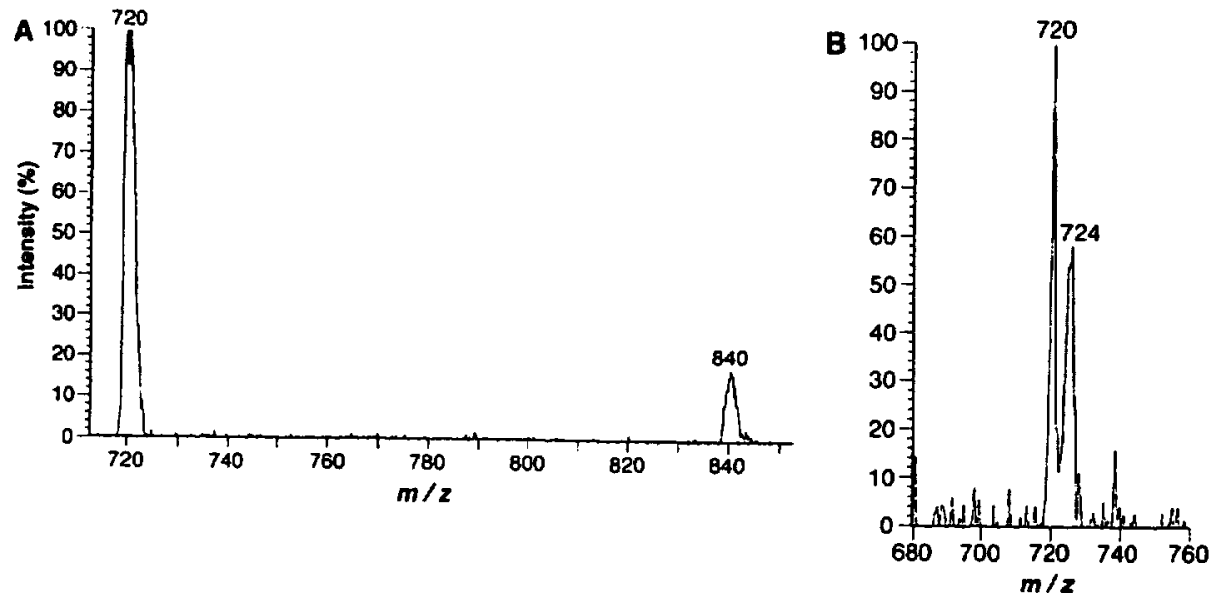

Fig. 1. (A) Laser desorption (reflectron) mass spectrum (LDMS) of the Dowling sample showing peaks at $\mathrm{m} / \mathrm{z}$ of 720 and $840 \mathrm{amu}$. Intensity is given in arbitrary units. The Dowling sample had significantly more $\mathrm{C}_{70}{ }^{+}\left(804 \mathrm{amu}\right.$ ) than the Capreol sample (the $\mathrm{C}_{70}{ }^{+}$peak for Capreol was barely above background). (B) The LDMS of the Capreol sample. By carefully calibrating the mass spectrometer at an acceleration voltage of $5 \mathrm{keV}$, we were able to observe a mass spectrum that included $\mathrm{C}_{60}{ }^{+}$and $\mathrm{C}_{60} \mathrm{He}^{+}$at $724 \mathrm{amu}$ (a peak for 724 amu was not observed in any of the authentic fullerene standards). This analysis maximizes the detection for $\mathrm{C}_{60}{ }^{+}$and $\mathrm{C}_{60} \mathrm{He}^{+}$, and thus the peak intensities shown are exaggerated and do not reflect the absolute abundances of the ions. Under the LDMS conditions, it is unlikely that $\mathrm{C}_{60} \mathrm{He}$ * would survive if $\mathrm{He}$ were bound to the exterior of the $\mathrm{C}_{60}{ }^{+}$molecule. These results suggest that $\mathrm{He}$ is in the interior of the Sudbury $\mathrm{C}_{50}{ }^{+}$molecule, indicating an endohedral complex (16). concentration $\left(37^{3} \mathrm{He}\right.$ atoms per $\left.10^{10} \mathrm{C}_{0}\right)$ observed, demonstrating that nuclear reaction implantation is not an effective mechanism for getting $\mathrm{He}$ into fullerenes.

The presence of extraterrestrial $\mathrm{He}_{(\mathrm{C})}$ in the Sudbury impact deposits suggests that fullerenes may indeed be present in some meteorites or comets and that fullerenes may also be a unique carrier of noble gases in certain extraterrestrial environments. In addition, on the basis of the He release and temperature-pressure stability estimates for

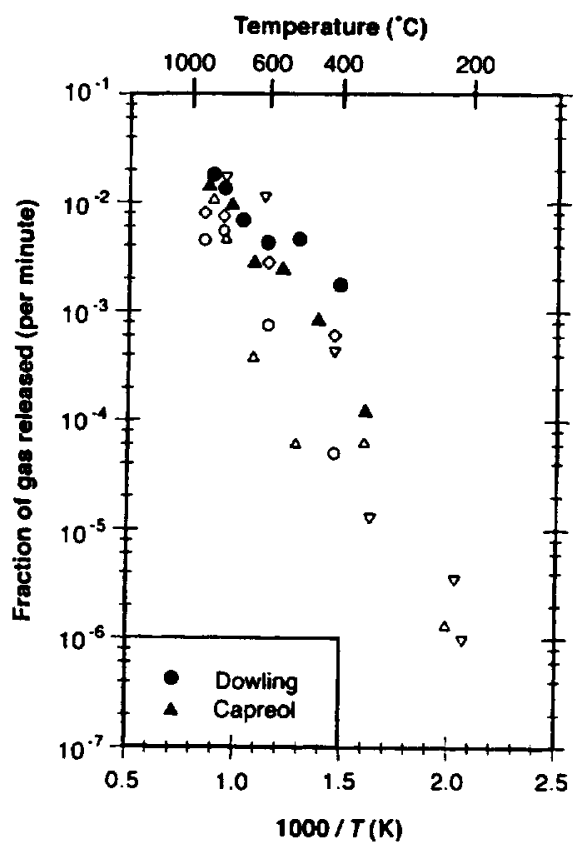

Fig. 2. Temperature ( $\mathrm{C}$-dependent ${ }^{3} \mathrm{He}$ release for the Capreol ( $\Delta$ ) and Dowling (O) samples. Open symbols are the release rates for the syn. thetic fullerenes $\left(C_{60}\right.$ and $\left.C_{70}\right)$ taken from $(8):(\nabla$ and $\angle){ }^{3} \mathrm{He},(\mathrm{O}){ }^{4} \mathrm{He}$, and $(r) \mathrm{Ne}$. 
$\mathrm{He}_{(\mathrm{O}}$ [see Fig. 2 and (8)], some portion of the Sudbury holide must have remained well below the $\mathrm{He} @ \mathrm{C}_{60}$ stability temperature $\left(1000^{\circ} \mathrm{C}\right)$. The survival of $\mathrm{He} @ \mathrm{C}_{60}$ during a bolide impact such as the one that created the Sudbury crater is unexpected (27) and suggests that the exogenous delivery of organic material to the early Earth may be more favorable than has been previously assumed. The extensive fragmentation of a bolide during passage through Earth's atmosphere may be one way of preserving some of the extraterrestrial organic material during an impact event.

An important remaining consideration is the type of environment that would favor fullerene formation. The diffuse interstellar medium (ISM) is a hostile environment, and several processes may act to destroy fullerenes (for example, sputtering or shocks). However, there is evidence for the existence of a solid form of $\mathrm{C}$ that is of the size of a large molecule or a small particle, having survival characteristics against ultraviolet photodissociation and destructive shocks (28). Whether this material is in the form of polycyclic aromatic hydrocarbons $(28,29)$ or is related to fullerene molecules (30) remains an intriguing question.

Because the Sudbury fullerenes exhibit ${ }^{3} \mathrm{He} /{ }^{4} \mathrm{He}$ ratios that exceed those associated with the solar wind and because of the high He pressure of incorporation $(\sim 1000$ torr at $1000^{\circ} \mathrm{C}$ ), we favor a scenario in which $\mathrm{He}$ is trapped in the Sudbury fullerenes before the condensation of the solar nebula (30). However, alternative mechanisms occurring in the ISM, such as spallation reactions and selective $\mathrm{He}$ implantation, may also be responsible for the higher than solar ${ }^{3} \mathrm{He} /{ }^{4} \mathrm{He}$ ratios. The paucity of $\mathrm{H}$ appears to be necessary to promote the $C$ shell closure required for fullerene formation (31). Environments in which the formation and preservation of fullerenes may be favorable $(30,31)$ include those for which the $\mathrm{H}$ concentrations are much lower than the mean cosmic abundance $\left(\mathrm{H} / \mathrm{He}<10^{-9}\right)$, the $\mathrm{C} / \mathrm{He}$ ratio is $\sim 0.004$, and the $\mathrm{C} / \mathrm{O}$ ratio is $>1$. These conditions are similar to the outflows from Wolf Rayet and $\mathrm{R}$ Coronae Borealis stars (30-33). Confirmation of a presolar origin for the Sudbury fullerenes will require the identification of anomalous isotopic compositions of $\mathrm{Ne}, \mathrm{Kr}$, and $\mathrm{Xe}$ [for example, the pure ${ }^{22} \mathrm{Ne}$ component (5)] that may be contained within the fullerene molecule (34) and precise determination of the Sudbury fullerene $C$ isotopic ratio.

\section{REFERENCES AND NOTES}

1. L. Becker et al., Science 265, 642 (1994).

2. U. Ott, R. Mack, S. Chang. Geochim. Cosmochim. Acta 45. 1751 (1981); S. Niemeyer and K. Marti,
Proc. Lunar Planet. Sci. Conf. 12. 1177 (1981).

3. D. C. Black and R. O. Pepin, Earth Planet. Sci. Lett 6. 395 (1969).

4. E. Anders, H. Higuchi, J. Gros, H. Takahashi. J. W. Morgan, Science 190, 1262 (1975); P. K. Swart, M M. Grady, C. T. Pillinger, R. S. Lewis. E. Anders, Nature 220. 406 (1983)

5. E. Zinner, B. Wopenka. S. Amari. E. Anders, Lunar Planet. Sci. 21. 1379 (1990): E. Anders and E. Zinner. Meteoritics 28. 490 (1993); E. Zinner. S. Amari. B. Wopenka, R. S. Lewis, ibid. 30. 209 (1995).

6. D. Heymann, Proceedings of the Seventeenth Lunar Planetary Science Conference, Part 1 (J. Geophys. Res. 91, 135 (1986)].

7. L. Becker, J. L. Bada, R. E. Winans, T. E. Bunch, Nature 372. 507 (1994). Fullerenes $\left(C_{60}\right.$ and $\left.C_{70}\right)$ were detected by laser desorption mass spectrometry (LDMS) in the Allende meteorite. The amount of $C_{B O}$ present was estimated at $0.1 \mathrm{ppm}$. The low concentrations of fullerenes extracted from Allende left insufficient amounts of fullerenes for noble gas measurements.

8. M. Saunders, H. A. Jimènez-Vázquez, A. J. Cross, R. J. Poreda, Science 259, 1428 (1993); M. Saunders, R. J. Cross, H. A. Jiménez-Vázquez, R. Shimsi, A. Kohng, ibid. 271, 1693 (1996). The initial measurements of He in synthetic fullerenes demonstrated that the isotopic composition of the $\mathrm{He}$ in the fullerene molecule was identical to that of the tank $\mathrm{He}$ used in the production of fullerenes. The only way to release the $\mathrm{He}$ once it is inside the fullerene molecule is to break one or more $\mathrm{C}-\mathrm{C}$ bonds, temporarily opening a window that allows the He to escape.

9. R. S. Lewis, J. Gros, E. Anders, Meteoritics 11, 320 (1976); J. I. Matsuda, R. S. Lewis, H. Takahashi, E Anders, Geochim. Cosmochim. Acta 44, 1861 (1980).

10. The Dowling samples were collected in Dowling Township, $300 \mathrm{~m}$ east of Highway 144 in the High Falls area, a type location for sampling the Onaping Black Member $\left(46^{\circ} 36^{\prime} \mathrm{N}, 81^{\circ} 24^{\prime} \mathrm{W}\right)$. The Capreol samples were collected in Capreol Township, $3 \mathrm{~m}$ west of Highway $545\left(46^{\circ} 42^{\prime} \mathrm{N}, 80^{\circ} 55^{\circ} \mathrm{W}\right)$.

11. We have considered the possibility that some of the Sudbury hullerenes may have opened up as a result of metamorphism (temperatures of $300^{\circ}$ to $400^{\circ} \mathrm{C}$ at pressures of 3 to 5 kbar in the Onaping rocks). It exchange of $\mathrm{He}$ took place, atmospheric $\mathrm{He}\left({ }^{3} \mathrm{He}\right.$ ${ }^{4} \mathrm{He} \sim 1.4 \times 10^{-9} \mathrm{o}$ or radiogenic $\left(\mathrm{HHe}^{4} \mathrm{He} \sim 10^{-6}\right)$ components typical for crustal rocks would have been added to the fullerene molecule.

12. The common approach for the demineralization of meteorites is to use HF.HCl acids to concentrate and isolate organic matter and $\mathrm{C}$. This procedure often leads to the formation of fluoride salts, which are insoluble and could potentially trap organics and carbonaceous materials. Here we selectively dissolved neoformed thuorides in a two-step process by reaction with $\mathrm{BF}_{3}$, a water-soluble gas, generated by the reaction of $\mathrm{H}_{3} \mathrm{BO}_{3}$ with $\mathrm{HF}$ and water. Then $\mathrm{BF}_{3}$ reacts with fluoride salts to form water-soluble lluoroborates. The demineralized portion (typically 80 to $100 \mathrm{~g}$ of powdered bulk rock treated with acid yields $\sim 1 \mathrm{~g}$ of carbonaceous residue) of the Onaping rock was then put into an extraction thimble, placed into a Soxhiet apparalus, and renuxed with touvene for 24 hours. The excess tohene was evaporated to dryness, leaving a small amount (microgram quantities) of residue. This resiche was then redissolved in lokuene and concen trated to $\sim 1 \mathrm{ml}$, yielding a bright reddish solution.

13. T. L. Robl and B. H. Davis, Org. Geochem. 20, 249 (1993). Additional steps for separating carrier phases in meteorites ffor example, removal of organic and amorphous $\mathrm{C}$ with $\mathrm{Cr}_{2} \mathrm{O}_{7}$ and removal of kerogen with $\mathrm{NaOH}$ or $\mathrm{H}_{2} \mathrm{O}_{2}$ \} would likely destroy any fullerenes that may be present in the meteorites. In addition, fullerenes are soluble in toluene and $\mathrm{CS}_{2}$ which are often used for the removal of polycyclic aromatic hydrocartoons and $S$, respectively. This may explain why fullerenes have not been previously identified as a carrier of noble gases in meteorites.

14. W. Kratschmer. L. D. Lamb. K. Fostiropoulos. D. R. Huffman. Nature 347, 354 (1990).

15. We obtained LDMS using a KRATOS (reflectron time-of-flight instrument at Argonne National Laboratories with unit mass resolution $(\mathrm{m} / \mathrm{sm})$ of up to
2000. A microliter of concentrated solution was placed on a stainless steel slide. Once the toluene had completely evaporated, the hulerene extract was transferred by a rapid sample change port into the high-vacuum chamber $\left(-2 \times 10^{-7}\right.$ to $2 \times 10^{-8}$ torr). Neutral and ionized particles were desorbed by a 337-nm ultraviolet nitrogen laser at low power densities $\left(10^{6} \mathrm{~W} / \mathrm{cm}^{2}\right)$. Mass spectra of positive ions emitted directly in the desorption process from the sample were collected. Blanks were run between sample analyses. Standards of $\mathrm{C}_{60}$ and $\mathrm{C}_{70}$ (Aldrich) were used to calibrate measurements of fullerenes detected in the sample extracts.

16. R. E Smalley. J Phys Chem. 95, 7564 (1991): T. Weiske, J. Husak, D. K. Bohme, H. Schwarz, Chem. Phys. Lett. 193. 97 (1991). They also observed a mass spectrum for synthetic endohedral fullerenes.

17. The toluene extracts containing the Sudbury tullerenes were loaded into a metal tube furnace within a glove box under a $\mathrm{N}_{2}$ atmosphere in preparation for noble gas analyses. After heating the samples in vacuum for 3 days at $100^{\circ} \mathrm{C}$, which completely removed any residual toluene, we then incrementally heated (60 min per step) the microgram quantities (about $200 \mu \mathrm{g}$ of $C_{60}$ per aliquot) of tullerene residues to release the trapped noble gases (8). Noble gases $\mathrm{He}, \mathrm{Ne}$, and Ar were cryogenically separated and then sequentially measured with a VG 5400 noble gas mass spectrometer fitted with a Johnston electron multiplier with pulse counting electronics on the axial collector $[R$. J. Poreda and $K$. A. Farley, Earth Planet. Sci. Lett. 113, 129 (1992)]. A resolution of $550(\mathrm{~m} / \mathrm{\Delta m})$ achieved complete baseline separation of ${ }^{3} \mathrm{He}^{+}$and $\mathrm{HD}^{+}$. Absolute abundances of ${ }^{3} \mathrm{He},{ }^{4} \mathrm{He},{ }^{36} \mathrm{Ar},{ }^{\circ} \mathrm{Ar}$, and ${ }^{22 \mathrm{Ne}}$ were $\mathrm{cal}-$ culated by peak height comparison to a standard of known size $\left(0.101 \mathrm{~cm}^{3}\right.$ of air at standard temperature and pressure) with an accuracy of $\pm 3 \%$. The small amount of ${ }^{22} \mathrm{Ne}$ and ${ }^{30} \mathrm{Ar}$ at all temperatures $\left(10^{-11}\right.$ and $10^{-10} \mathrm{~cm}^{3}$, respectively) was equivalent to the average blank. Average blank levels were $1 \times$ $10^{-10} \mathrm{~cm}^{3}$ for ${ }^{4} \mathrm{He}$ and $2 \times 10^{-18} \mathrm{~cm}^{3}$ for ${ }^{3} \mathrm{He}$. The contribution of adsorbed atmospheric $\mathrm{He}$ can be estimated from the measured ${ }^{22} \mathrm{Ne}$ and the $4 \mathrm{He} /$ ${ }^{22} \mathrm{Ne}$ ratio in air of -3.1 . In all of the temperature steps above $200^{\circ} \mathrm{C}$, this contribution was negligible $\left(<1 \%\right.$ of ${ }^{4} \mathrm{He}$ and $<0.01 \%$ of ${ }^{3} \mathrm{He}$ ). In comparison to the fullerene toluene fractions, heating $10 \mathrm{mg}$ of the bulk acid residue to $800^{\circ} \mathrm{C}$ released ${ }^{3} \mathrm{He}$ and ${ }^{4} \mathrm{He}$ at levels about three times the extraction blank.

18. Atmospheric isotopic ratios of Ne and A were measured for the Dowling and Capreol samples in all temperature fractions. The measured gas indicates that the presence of an adsorbed atmospheric component or that a certain percentage of the fullerene molecules has cpened up over geologic time, allowing atmospheric gases to be incorporated. Blank levels of ${ }^{22} \mathrm{Ne}$ were about $10^{5}$ times the blank levels for ${ }^{3} \mathrm{He}\left(-10^{-11} \mathrm{~cm}^{3}\right.$ for Ne versus $-10^{-16} \mathrm{~cm}^{3}$ for $\mathrm{He}$ ). If the anomalous gas component has a solar ${ }^{3} \mathrm{He} /{ }^{22} \mathrm{Ne}$ ratio of $1.3 \mathrm{~m}$. Ozima and F. Podosek, in Noble Ges Geochemistry (Cambridge Univ. Press. Cambridge, 1983)], then we need to achieve a factor of 10 reduction in our ${ }^{22} \mathrm{Ne}$ background to observe any anomalous $\mathrm{Ne}$ isotopic ratios.

19. Analyses of these acid residues by transmission electron microscopy indicated that there were no microdiamonds. In addition, we did not observe microdiamonds or $\mathrm{SiC}$ in the tohene fractions.

20. 8. A. Marnyrin and L. N. Tolstikin, in Helium Isotopes in Nature (Elsevier, Amsterdam, 1984): J. P. Benkert. H. Baur, P. Signer, R. Wieler, J. Geophys. Res. 98. 13147 (1993): T. D. Swindle, in Meteorites and the Earty Solar System, J. F. Kerridge and M. S. Matthews. Eds. (Univ. of Arizona Press. Tuscon, 1988), pp. 535-564.

21. W. Rison and H. Craig. Earth Planet. Sci. Lett. 66. 367 (1983); C. J. Allegre, T. Staudacher, P. Sarda, M. Kur. Nature 303, 762 (1983); M. D. Kur. W. J. Jenkins. S. R. Han, D. Clague. Earth Planet. Sci. Left. 66, 388 (1983).

22. A. O. Nier and D. J. Schlutter, Meteorilics 27, 166 (1992); - D. E. Brownlee. Geochim. Cosmochim. Acta 54, 173 (1990); M. Ozima, M. Takayanagi. S. Zashu, S. Amari, Nature 311. 449 (1984); K. A. Farley, ibid. 376. 153 (1995). 
23. Once the fullerenes were deposited in the Sudbury structure (Onaping Formation), they were protected from oxidation and irradiation by a surrounding sulfide-silicate matrix. which allowed them to survive to the present (1).

24. This calculation uses an average cosmic-ray-induced crustal production [T. E. Cerling and H. Craig. Annu. Rev. Earth Planet. Sci. 22. 273 (1994)) of ${ }^{3} \mathrm{He}$ determined for siticates (rate of 100 atoms per gram per year) at the latitude and altitude of Sudbury. The efficiency of the recoil of cosmic-ray ${ }^{3} \mathrm{He}$ from the silicate matrix into the $\mathrm{C}_{60}$ structure is not possible to evaluate.

25. D. Lal, Earth Planet. Sci. Lett. 96. 1 (1989). The rate of ${ }^{3}$ He production in this nuclear reaction is a complicated function of $\mathrm{Li}, \mathrm{U}$, and Th concentrations. but for average crustal rocks (such as the Black Member Onaping Formation) with a $U$ content of $1.25 \mathrm{ppm}$, $T \mathrm{~h} / \mathrm{U}=4$, and a Li content of $20 \mathrm{ppm}$, the rate of production can be approximated by the $\mathrm{U}$ concentration, the ${ }^{4} \mathrm{He}$ production rate $\left[{ }^{4} \mathrm{He}\right.$ (in cubic centimeters per gram) $=2.35 \times 10^{-13} \times U$ $(p p m) \times$ time (in years) and the average ${ }^{3} \mathrm{He}^{/ 4} \mathrm{He}$ ratio for production in crustal rocks $\left(1 \times 10^{-8}\right)$. Over a period of $2 \times 10^{\circ}$ years, the amount of ${ }^{3} \mathrm{He}$ produced was $1.6 \times 10^{8}$ atoms per gram of rock. If terrestrial incorporation of ${ }^{3} \mathrm{He}$ (initially as ${ }^{3} \mathrm{H}$ ) is important, then approximately $4 \%$ of the total ${ }^{3} \mathrm{He}$ production in the Onaping host rock ultimately ends up within the fullerene molecule (measured $3 \mathrm{He}$ concentration is 7.4 million atoms of ${ }^{3} \mathrm{He}$ per gram of rock). For randomly distributed $\mathrm{Li}$ atoms and fullerene molecules in the Onaping host rock. the probability that the $2.7 \cdot \mathrm{MeV}{ }^{3} \mathrm{H}$ atom (recoil distance of $10^{-6} \mathrm{~m}$ ) will intersect a $\mathrm{C}_{60}$ molecule is close to 1 in $10^{4}$. This model assumes a random distribution of $\mathrm{C}_{80}$ (about 2500 molecules) within a sphere of radius $10^{-6} \mathrm{~m}$ and that every interaction of ${ }^{3} \mathrm{H}$ with a $\mathrm{C}_{60}$ molecule results in ${ }^{3} \mathrm{H}$ incorporation. One must envision an incorporation mechanism that is highly selective for ${ }^{3} \mathrm{He}$ relative to ${ }^{4} \mathrm{He}$ from $U$ decay. We thus consider the terrestrial production and implantation of ${ }^{3} \mathrm{He}$ to be an unrealistic mechanism for the Sudbury fullerenes.

26. H. A. Jiménez-Vásquez, R. J. Cross, M. Saunders R. J. Poreda, Chem. Phys. Lett. 229, 111 (1994).

27. C. Chyba and C. Sagan, Nature 355, 125 (1992); C. F. Chyba, P. J. Thomas, L. Brookshaw, C. Sagan, Science 249, 366 (1990)

28. The fullerene cation $\mathrm{C}_{60}$ + has been identified in two new infrared emission features in the interstellar medium (B. H. Foing and P. Ehrenfruend, Nature 369 296 (1994); T. P. Snow and A. N. Witt, Science 270 1455 (1995); A. G. G. M. Tielens, in NASA Conf. Publ. 3061 (1990), vol. 1, p. 59.

29. L. J. Allamandola, A. G. G. M. Tielens, J. R. Barker, Astrophys. J. Suppl. Ser. 71, 733 (1989).

30. H. Kroto, Science 242, 1139 (1988)

31. D. K. Bohme, Chem. Rev. 92,1487 (1992); S. Petrie, G. Javahery, D. K. Bohme, Astron. Astrophys. 271, 662 (1993).

32. J. P. Hare and H. W. Kroto, Acc. Chem. Res, 25, 106 (1992).

33. Carbon soot formation in these stars is expected to be initiated through the formation of polyenes lacetylene-like $\mathrm{C}$ chains without $\mathrm{H}$, such as $\mathrm{C}_{2}, \mathrm{C}_{3}$, and $\mathrm{C}_{4}$ (30)]. The lack of $\mathrm{H}$ minimizes saturation of dangling $C$ bonds, allowing pentagons to be incorporated into the aromatic structure. The introduction of pentagons induces warping and curling of the aromatic planes, which would lead to closure and fullerene formation. It was the laboratory experiments used to probe these questions (laser ablation of graphite in an inert environment) that resulted in the initial dis. covery of fullerenes $\left(\mathrm{C}_{60}\right.$ and $\left.\mathrm{C}_{70}\right)$ and the proposal that this unique torm of $\mathrm{C}$ may be imvolved in the $\mathrm{C}$ nucleation process $(30-32)$

34. Recent calculated equilibrium constants for the incorporation of noble gas atoms inside the $C_{60}$ molecule (two different models were used to calculate the potential between the noble gas atom and each $C$ atom) indicate that the potentials agree for encapsulation of He and $\mathrm{Ne}$ but disagree strongly for encapsulation of $\mathrm{Kr}$ and $\mathrm{Xe}$. If this is the case, then the $\mathrm{C}_{\mathrm{co}}$ molecule may preferentially incorporate the lighter noble gases over the heavier noble gases $(H$. A.
Jiménez-Vásquez and R. J. Cross. J. Chem. Phys., in press).

35. The work of L.B. was supported by the National Research Council. This work was also supported by a grant for a National Aeronautics and Space Administration Specialized Center of Research and Training in Exobiology at the University of California at San Diego (J.L.B.) and by grants from the National Science Foundation (R.J.P.). L.B. thanks R. E. Winans for use of the mass spectrometer facility at Argonne National Laboratory and B. O. Dressler and W. $V$ Peredery for assistance in the collection of the Sud bury samples analyzed in this study. We also thank $\mathrm{T}$. Bunch for technical assistance with the Sudbury samples and many helpfui discussions and N. Keon. A. Hunt, and P. McGinnity lor anahytical assistance.

7 November 1995: accepted 27 February 1996 